\title{
Examination of Surface Residuals Obtained during Re-Lubrication of the International Space Station (ISS) Solar Alpha Rotary Joint (SARJ)
}

\author{
J. L. Golden* and J. E. Martinez** \\ *Boeing Research \& Technology, 13100 Space Center Blvd, MC HB3-20, Houston, TX 77059 \\ **Materials \& Processes Branch, MC ES4, NASA Johnson Space Center, Houston, TX 77058
}

The starboard SARJ mechanism on the ISS suffered a premature lubrication failure, resulting in widespread loss of the nitride case layer on its 10.3 meter circumference, $15-5 \mathrm{PH}$ steel race ring [1, 2]. To restore functionality, vacuum-stable grease was applied on-orbit, first to the port SARJ mechanism to save it from the damage suffered by the starboard mechanism. After 3 years of greased operation, telemetry indicated that the port mechanism required relubrication, so part of that process included sampling each of the three race ring surfaces to evaluate any wear debris recovered and the state of the originally applied grease. Extensive microscopic examination was conducted, which directed subsequent microanalysis of particulate.

Since the SARJ mechanism operates in the vacuum of space, a sampling method and tool had to be developed for use by astronauts while working in the extravehicular mobility unit (EMU). The sampling tool developed was a cotton terry-cloth mitt for the EMU glove, with samples taken by swiping each of the three port SARJ race-ring surfaces. The sample mitts for each surface were folded inward after sampling to preserve sample integrity, for return and ground analysis. The sample mitt for what is termed the "outer canted" surface of the SARJ race-ring is shown in Figure 1. Figure 1 also demonstrates how increasing levels of magnification were used to survey the contamination removed in sampling, specifically looking for signs of wear debris or other features which could be further evaluated using Scanning Electron Microscopy (SEM) methods. The most surprising overall result at this point in the analysis was the relatively small amounts of grease recovered during sampling. It is clear that the mechanism was not operating with surplus lubricant.

Obviously, evidence of molybdenum disulfide $\left(\mathrm{MoS}_{2}\right)$, a major component in the grease applied, was prevalent in the analysis conducted. But a small amount of mechanism wear debris was observed. Figure 2 shows an example of a region of concentrated wear debris. Although some $\mathrm{MoS}_{2}$ is observed, most of the contaminant in this location is nitrided $15-5 \mathrm{PH}$ steel, as verified by the associated chemical analysis. High oxygen content was also observed which, when associated with the apparent friable nature of the steel material, suggests that this contaminant could be quite old, perhaps even associated with the mechanism's original manufacture and acceptance testing.

Additional microscopic analysis is shown in Figure 3, for two additional debris particles examined. The first particle is shown in two images: the first using variable pressure SEM imaging and showing the nitrided 15-5PH steel particle trapped among the sampling-mitt cotton fibers; and the second using secondary back-scatter imaging and a slightly higher magnification, which shows residuals of grease contamination on the steel particle and evidence of oxidation. The second of the particles shown in Figure 3 was the largest of the metallic debris particles observed in the investigation. In other particulate analyses, evidence of gold from the original mechanism lubrication system was observed, but very few such indications were found. 
Overall, results indicated no alarming evidence of wear, though some indications of stress on the lubricant itself were chemically observed (likely because of the limited quantity originally applied). The SARJ system is currently in normal operation with a regular relubrication cycle [3].

\section{References}

[1] Wright, M.C., "International Space Station (ISS) Expedition 16 Starboard Solar Alpha Rotary Joint (s-SARJ) Debris Analysis,” Internal report KSC-MSL-2008-0099, (2008).

[2] C. Enriquez, "International Space Station Solar Alpha Rotary Joint Anomaly Report", ISS Program report D684-13412-01, (2009).

[3] The authors acknowledge the International Space Station program and the SARJ Operations Team for supporting this activity (all Boeing activity is under the NAS15-10000 contract).

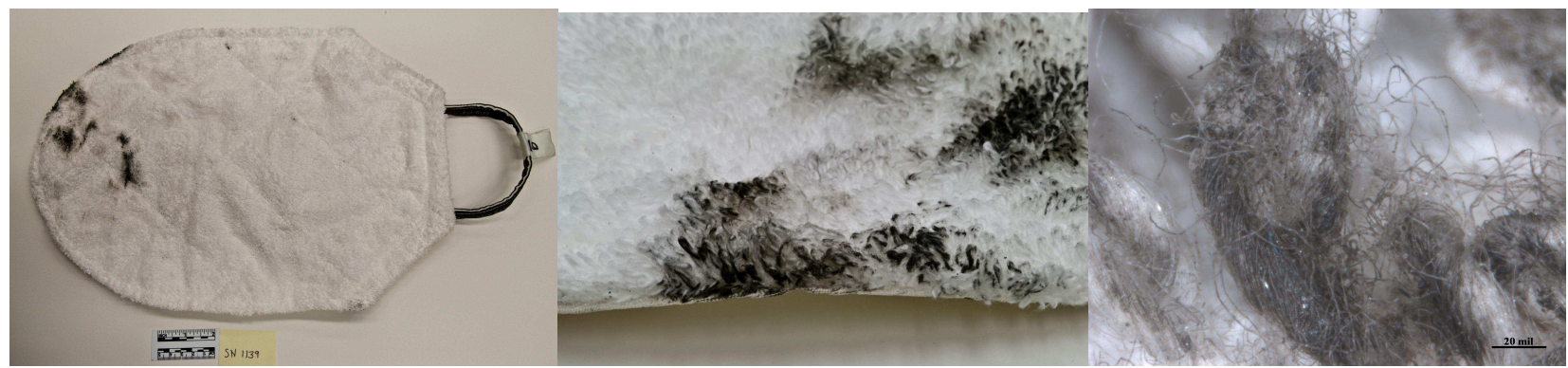

FIG. 1. EVA mitt containing grease sample from the outer canted surface of the SARJ race ring, showing increasing levels of magnification used to for initial evaluation.
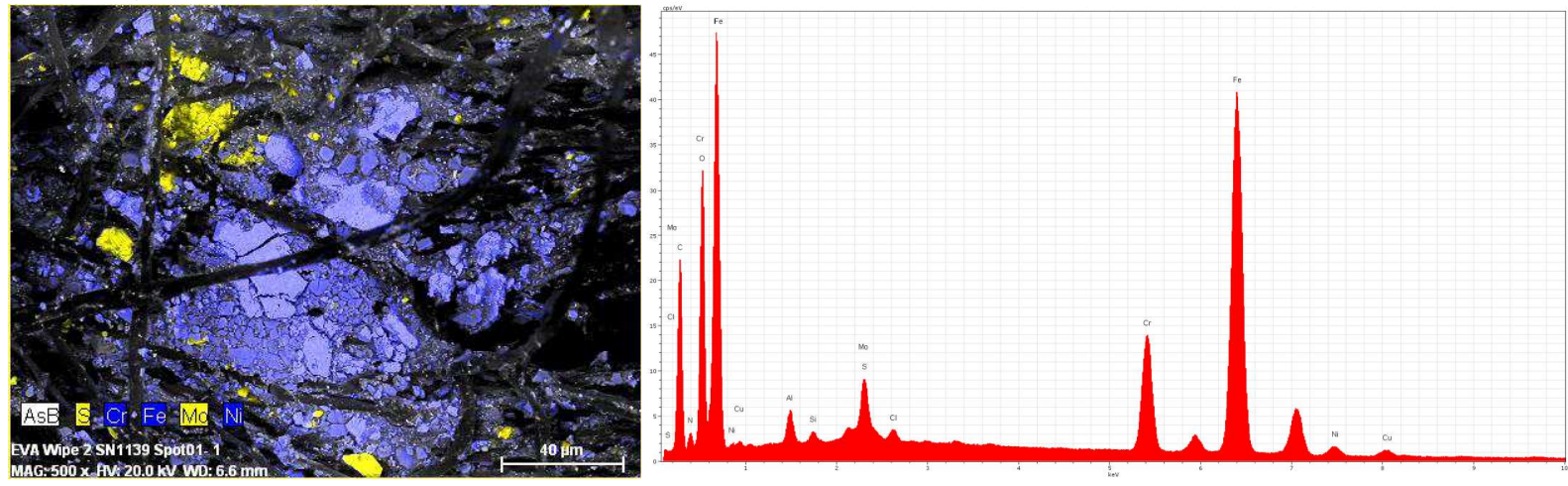

FIG. 2. SEM and elemental analysis of a typical region of contaminant sample from the SARJ outer canted surface. A mixture of $\mathrm{MoS}_{2}$ (grease) and nitrided 15-5PH steel (wear debris) is indicated.

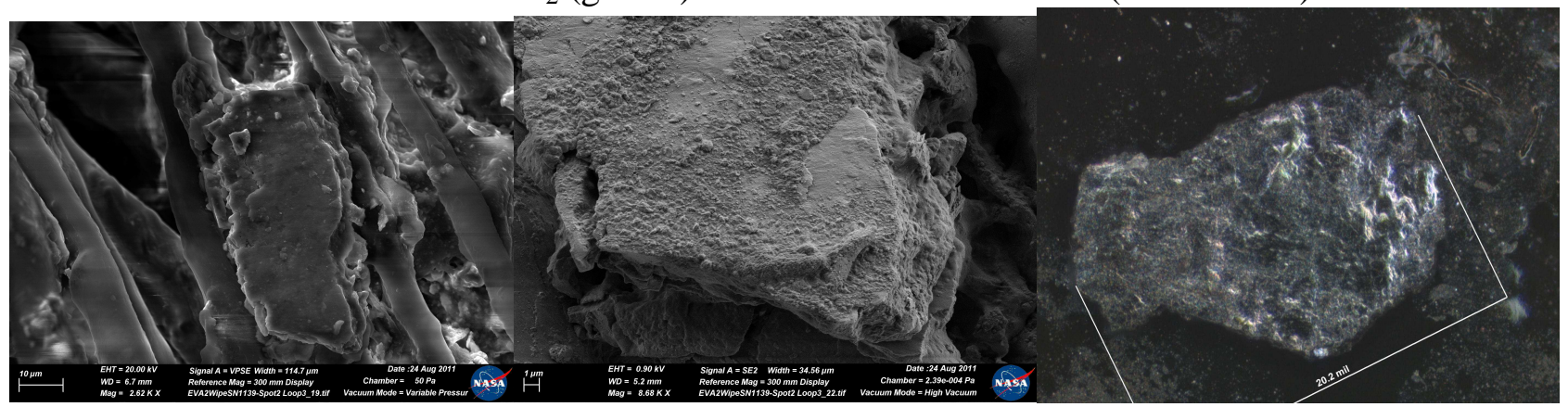

FIG 3. Examples of two wear debris particles. The first two images are of the same particle, shown using the SEM in variable pressure mode, followed by a secondary backscatter image. The third SEM shows the largest race-ring debris particle observed during this investigation. 


\section{Rechorah 8. Tathnninai}

Examination of Surface Residuals

Obtained during Re-Lubrication of the

International Space Station (ISS)

Solar Alpha Rotary Joint (SARJ)

J. L. Golden, Ph.D. - Boeing Research \& Technology

J. E. Martinez - NASA Johnson Space Center / ES4

M\&M 2012 / P-06 Failure Analysis of Structural Materials Phoenix, AZ 31 August 2012 


\section{Examination of Surface Residuals Obtained during Re-Lubrication of the ISS SARJ}

\section{- Acknowledgements}

- All Boeing and Boeing subcontractor activity conducted under NASA contract

- NAS15-10000

- Original SARJ Failure Analysis was an Intense Team Effort, conducted from October 2007 through January 2010.

- NASA JSC ES4, MSFC EM30, KSC NE

- NASA Engineering \& Safety Center (NESC)

- Boeing

- Lockheed-Martin

- ATK

- Numerous Supportive Subcontractors

- Thanks to ISS Mission Integration \& Operations (OC) and EVA Systems (EC) and the EVA Office (XA) for obtaining samples.

- M\&M conducted by and at the NASA JSC Materials \& Process (ES4) Laboratory 


\section{Examination of Surface Residuals Obtained during Re-Lubrication of the ISS SARJ}

\section{Summary of Presentation}

- Brief Background on the Failure

- International Space Station; Solar Alpha Rotary Joint

- On-Orbit Sampling Approach

- Laboratory Analyses

- Optical Microscopy Survey

- SEM and elemental analyses 


\section{Examination of Surface Residuals Obtained during Re-Lubrication of the ISS SARJ}

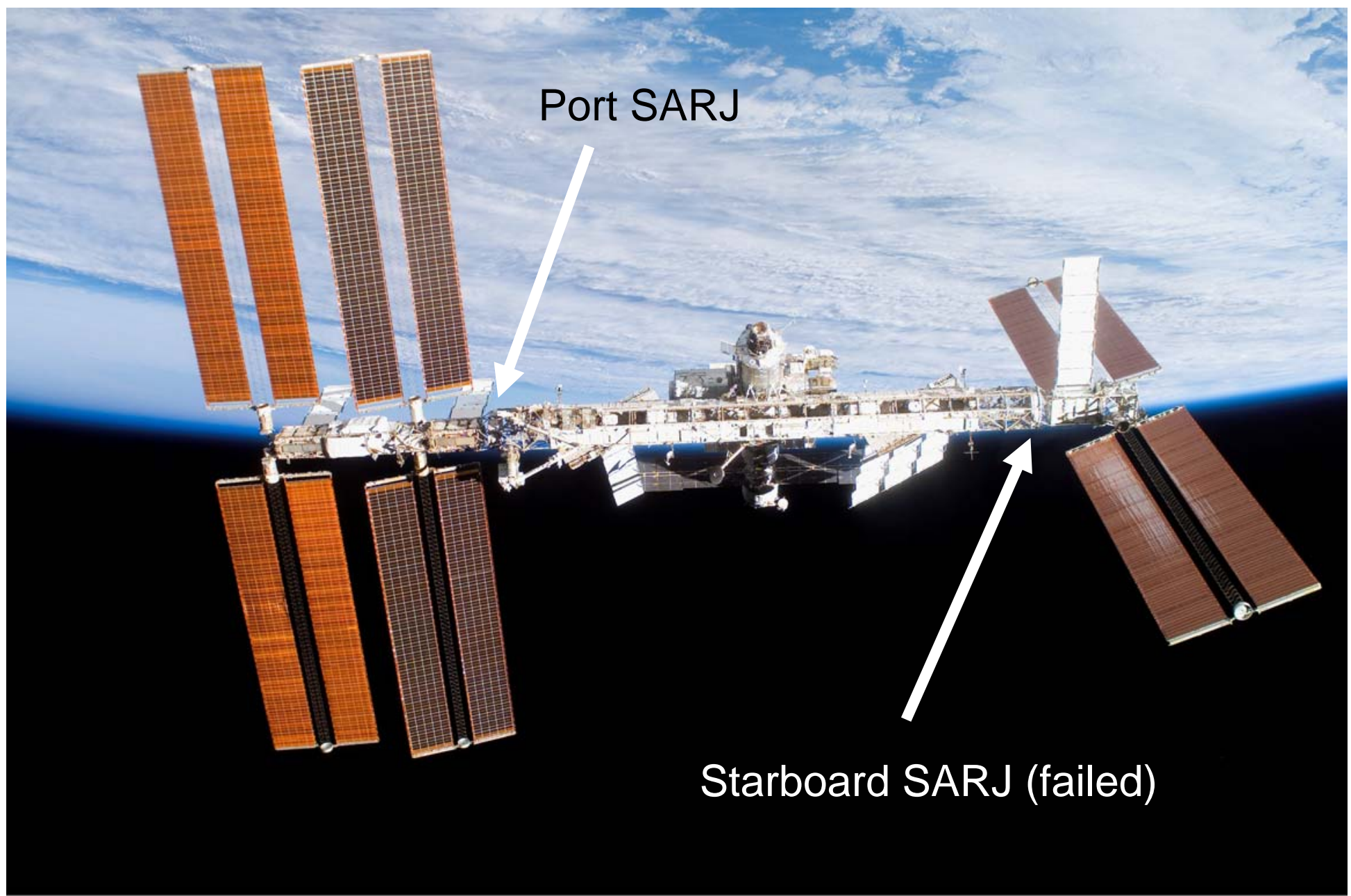

S120E008526

ISS 2007 Configuration: Solar Alpha Rotary Joint (SARJ) Locations 


\section{Examination of Surface Residuals Obtained during Re-Lubrication of the ISS SARJ}

The Solar Alpha Rotary Joint (SARJ) is used to rotate the outboard Solar Array Wings (SAW) and transfer generated power to the ISS pressurized elements
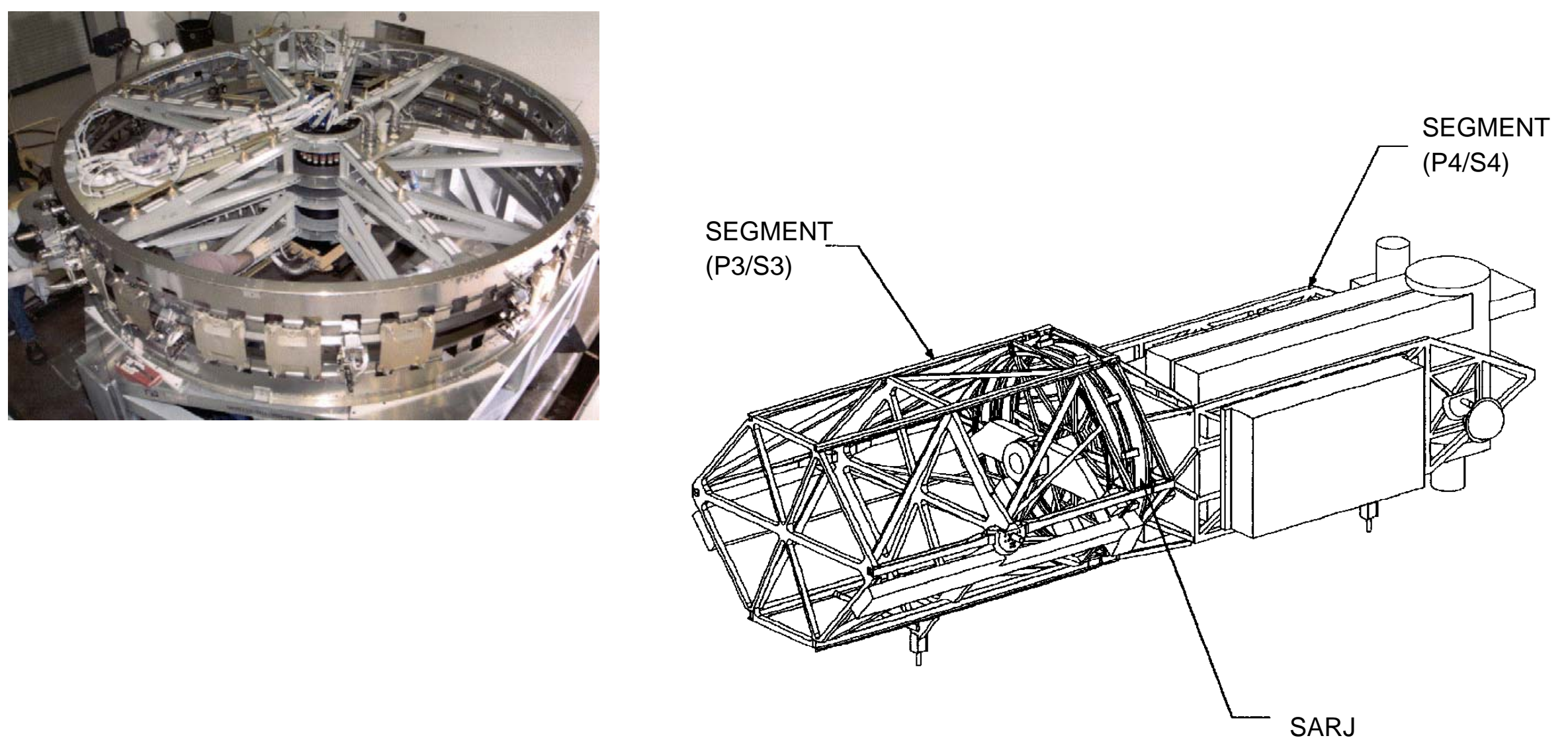


\section{Examination of Surface Residuals Obtained during Re-Lubrication of the ISS SARJ}

Nitrided 15-5PH Race Ring

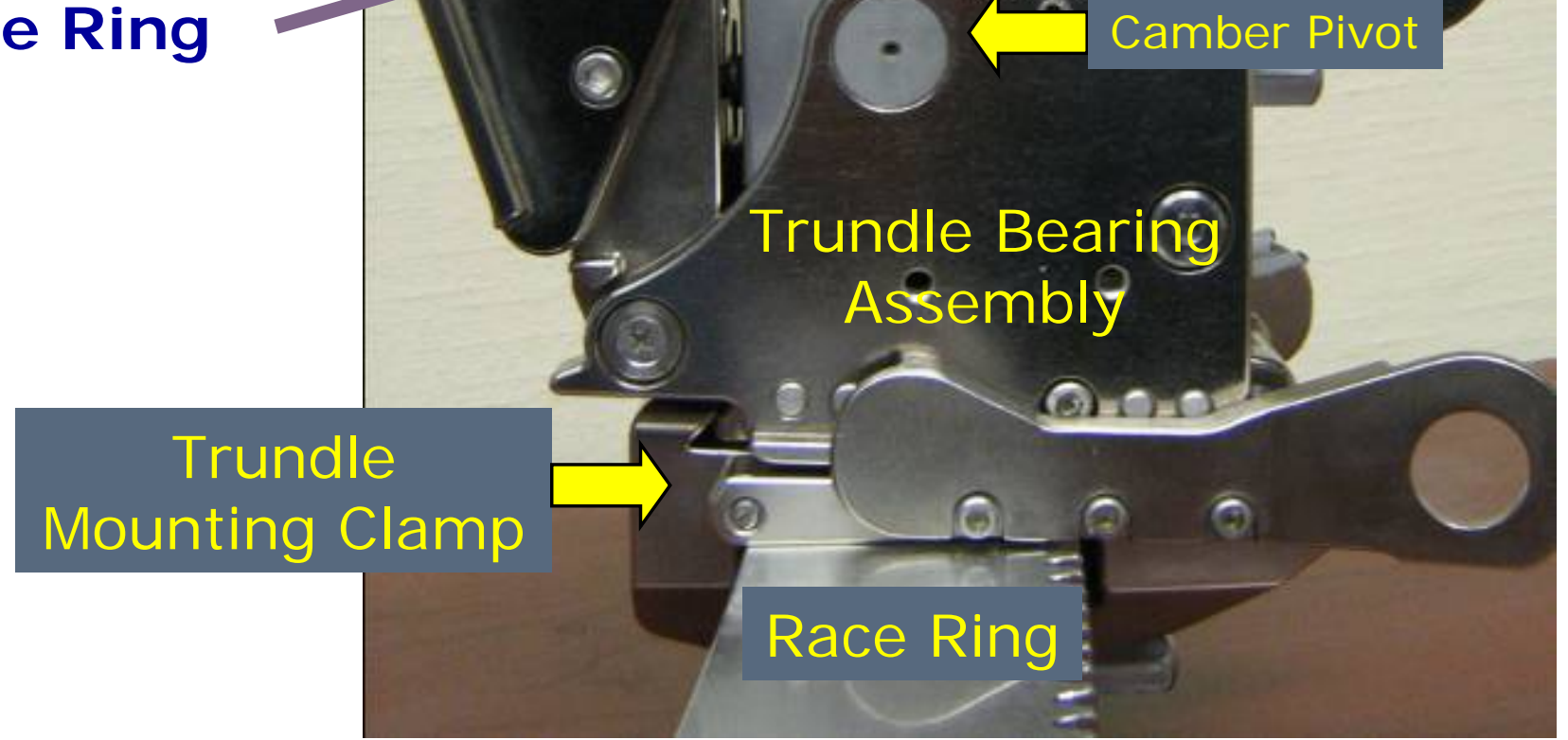




\section{Examination of Surface Residuals Obtained during Re-Lubrication of the ISS SARJ}

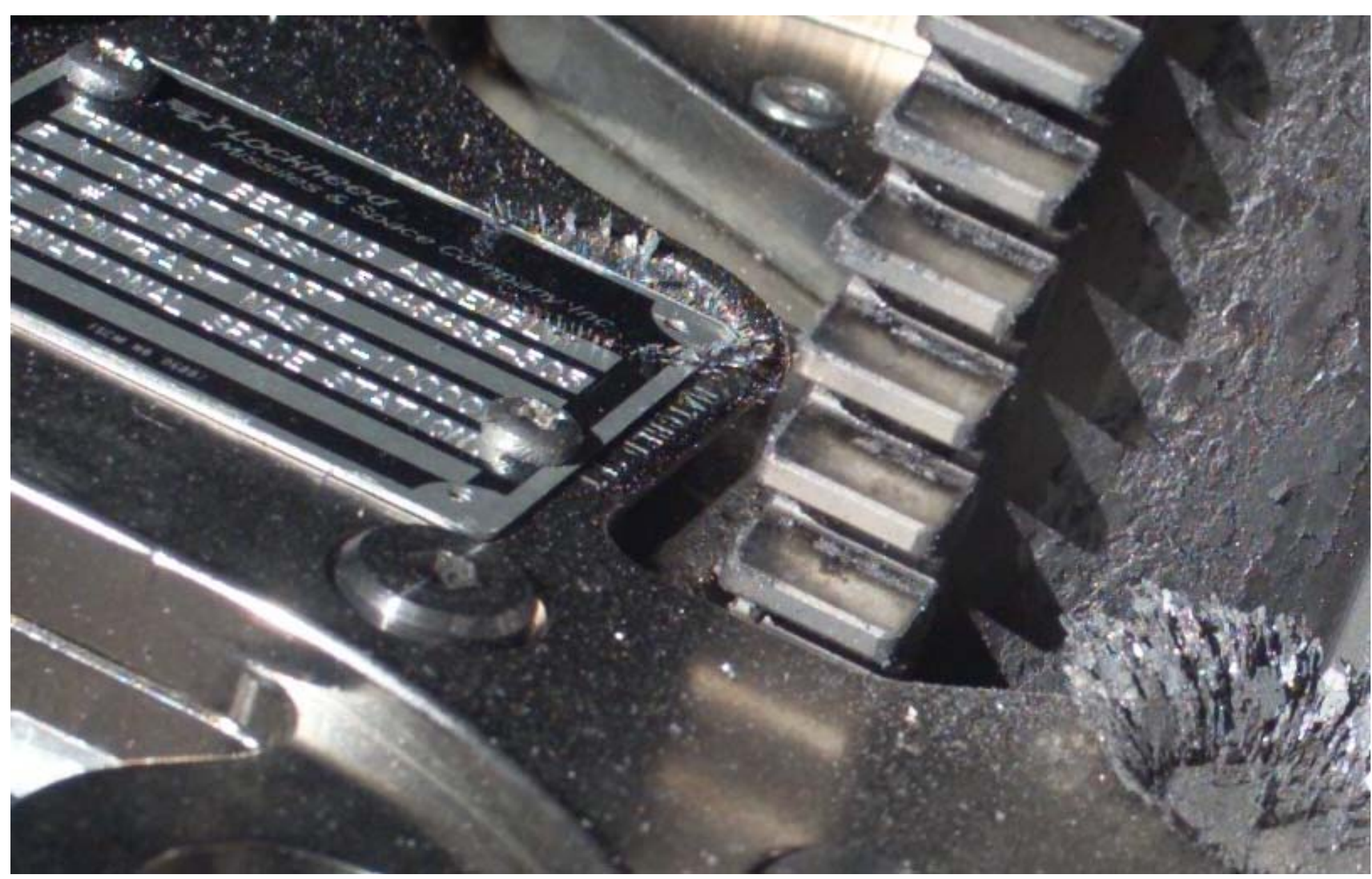

Initial Examination of Starboard SARJ Race Ring Damage 


\section{Examination of Surface Residuals Obtained during Re-Lubrication of the ISS SARJ}

- Physical Characteristics of the Failure Debris

- Particle Size Distribution

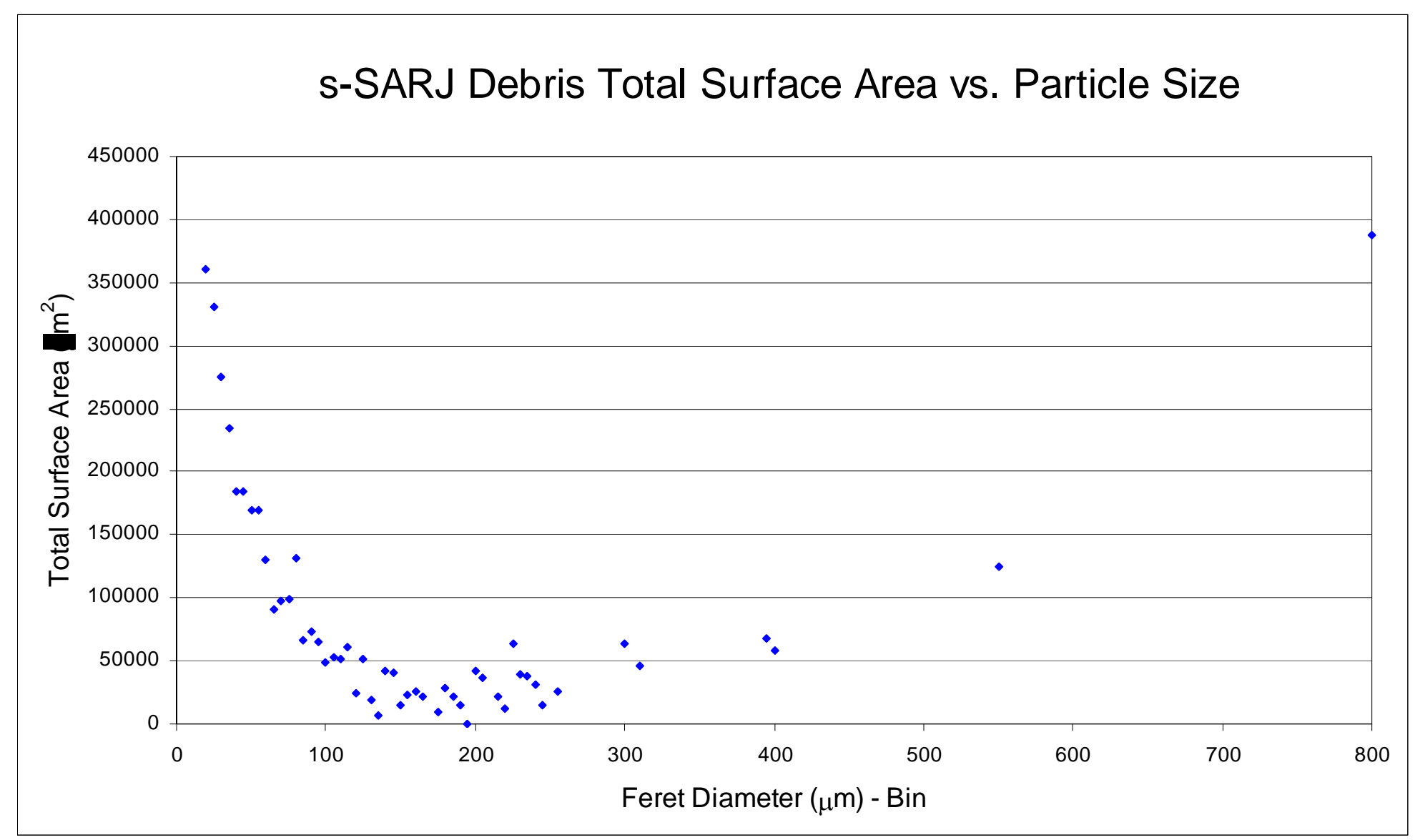




\section{Examination of Surface Residuals Obtained during Re-Lubrication of the ISS SARJ}

- Physical Characteristics of the Failure Debris - Cont. - Particle Size Distribution - Both views are 100X

Representative area of "fine" debris $(<100 \mu \mathrm{m})$

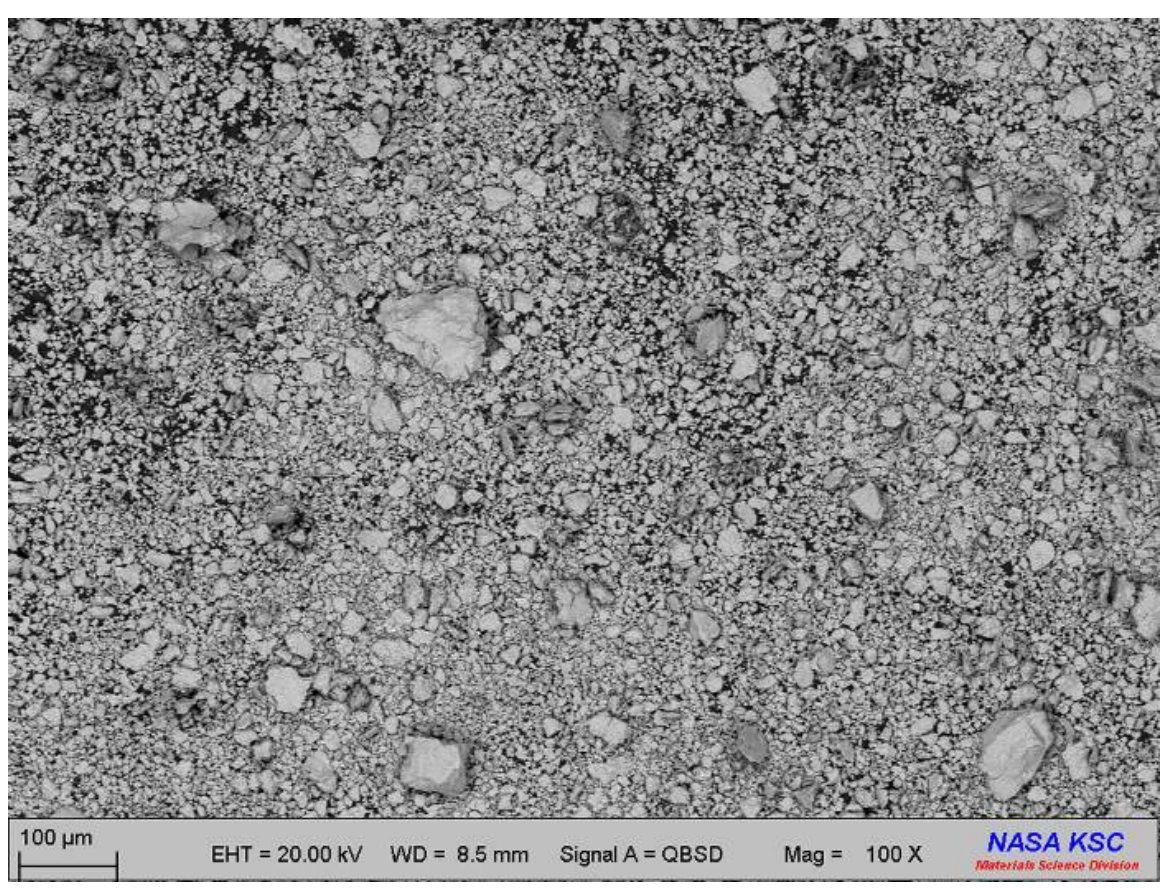

Representative area of all debris; broad particle size distribution

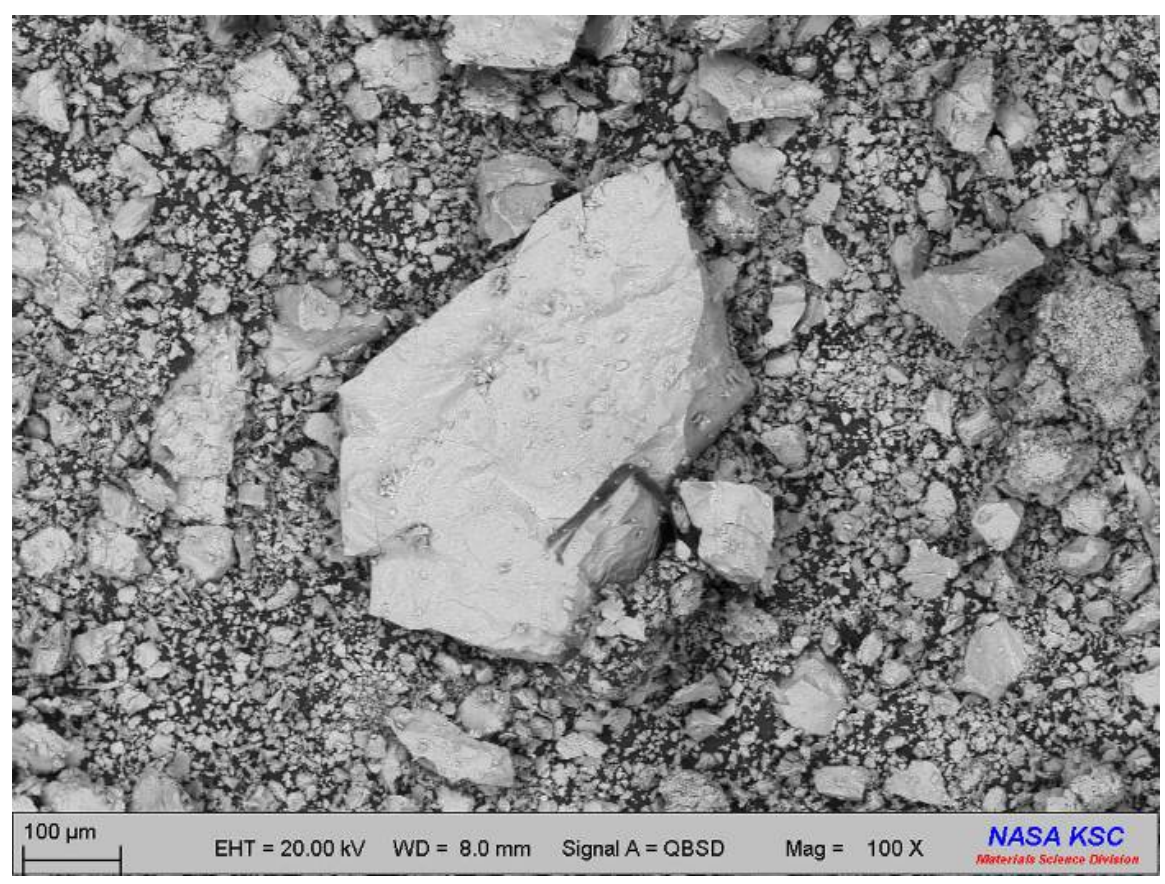

ASM Houston Failure Analysis Seminar J.L.Golden 03 April 20129 


\section{Examination of Surface Residuals Obtained during Re-Lubrication of the ISS SARJ}

- Summary of Mechanism Failure Analysis

- The nitride surface of the SARJ race rings had unrecognized subsurface flaws susceptible to fracture initiation.

- The lubrication system selected in design was not robust enough to maintain friction control.

- Once friction control was lost, subsurface loads moved up into the interface of and within the nitride layer.

- Spalling probably initiated at subsurface flaws, generating particles which exacerbated the surface stresses, leading to spalling of most of the nitride layer in a relatively short time.

- Weak magnetic forces in the microgravity environment held released particles within the mechanism, leading to crushing of the larger "chip" particles into fines and eventual agglomeration of those fines. 


\section{Examination of Surface Residuals Obtained during Re-Lubrication of the ISS SARJ}

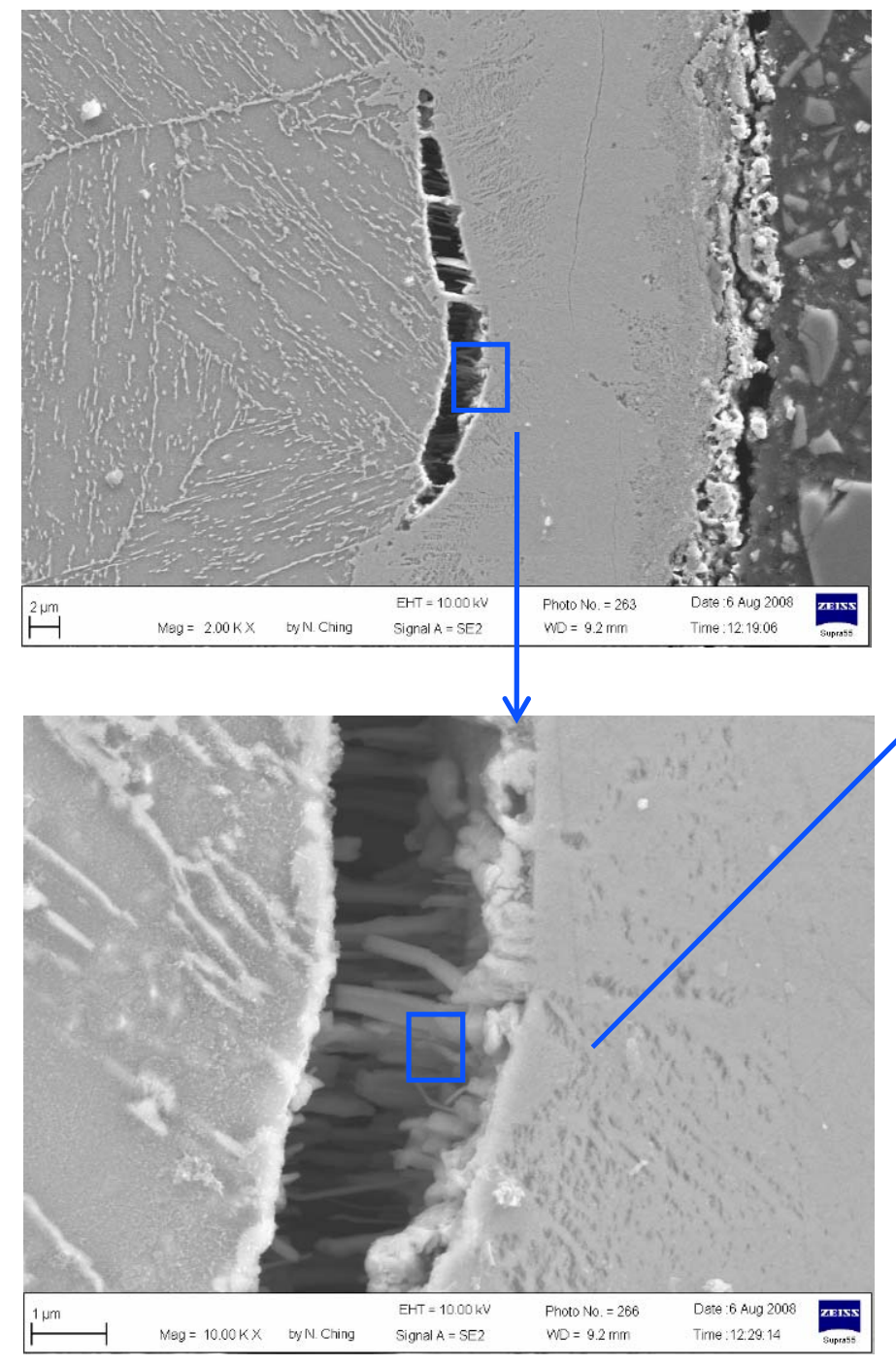

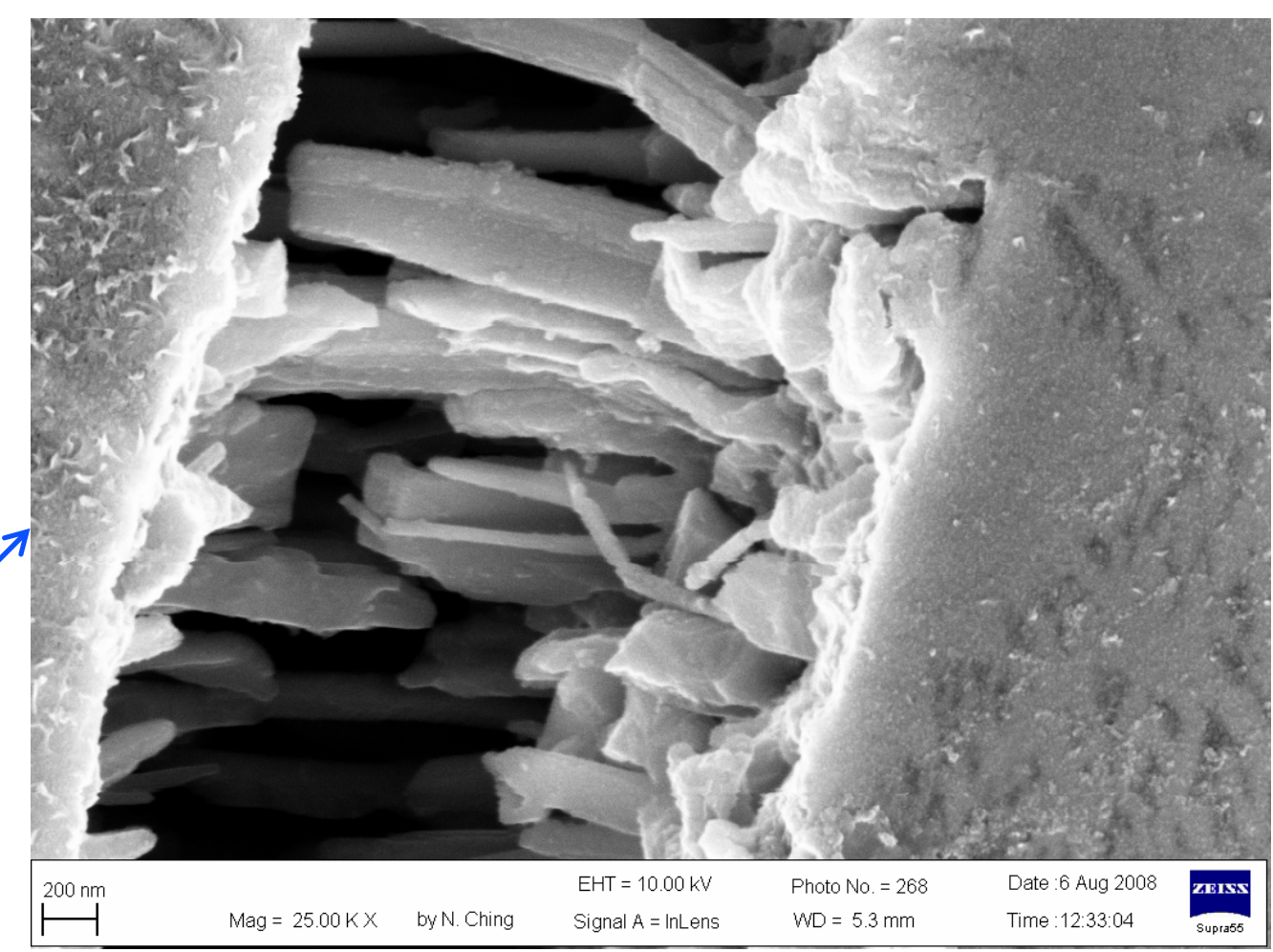

Polished metallographic sample showing discontinuous intergranular separation (DIGS). The degree of porosity and the type scaffolding structure inside each DIGS varies, and at times appears as a nanostructure. 


\section{Examination of Surface Residuals Obtained during Re-Lubrication of the ISS SARJ}

- How did we recover SARJ mechanisms?

- We lubricated race ring surfaces using a $\mathrm{MoS}_{2}$ + PTFE filled vacuum-stable grease, performed by EVA.

- We applied this grease to the Port SARJ first, as soon as we could, and believe that we saved it from the spalling failure.

- We cleaned the damaged Starboard race ring using the same grease to help capture particulate, prior to final lubrication.

- We replaced all of the Starboard SARJ trundle bearing assemblies as part of the cleaning process.

- After several operation test runs of increasing duration with analysis of telemetry to determine the structural viability of the damaged race ring, the Starboard SARJ returned to nominal operation early 2010.

- Starboard SARJ performance since is characterized as good. 


\section{Examination of Surface Residuals Obtained during Re-Lubrication of the ISS SARJ}

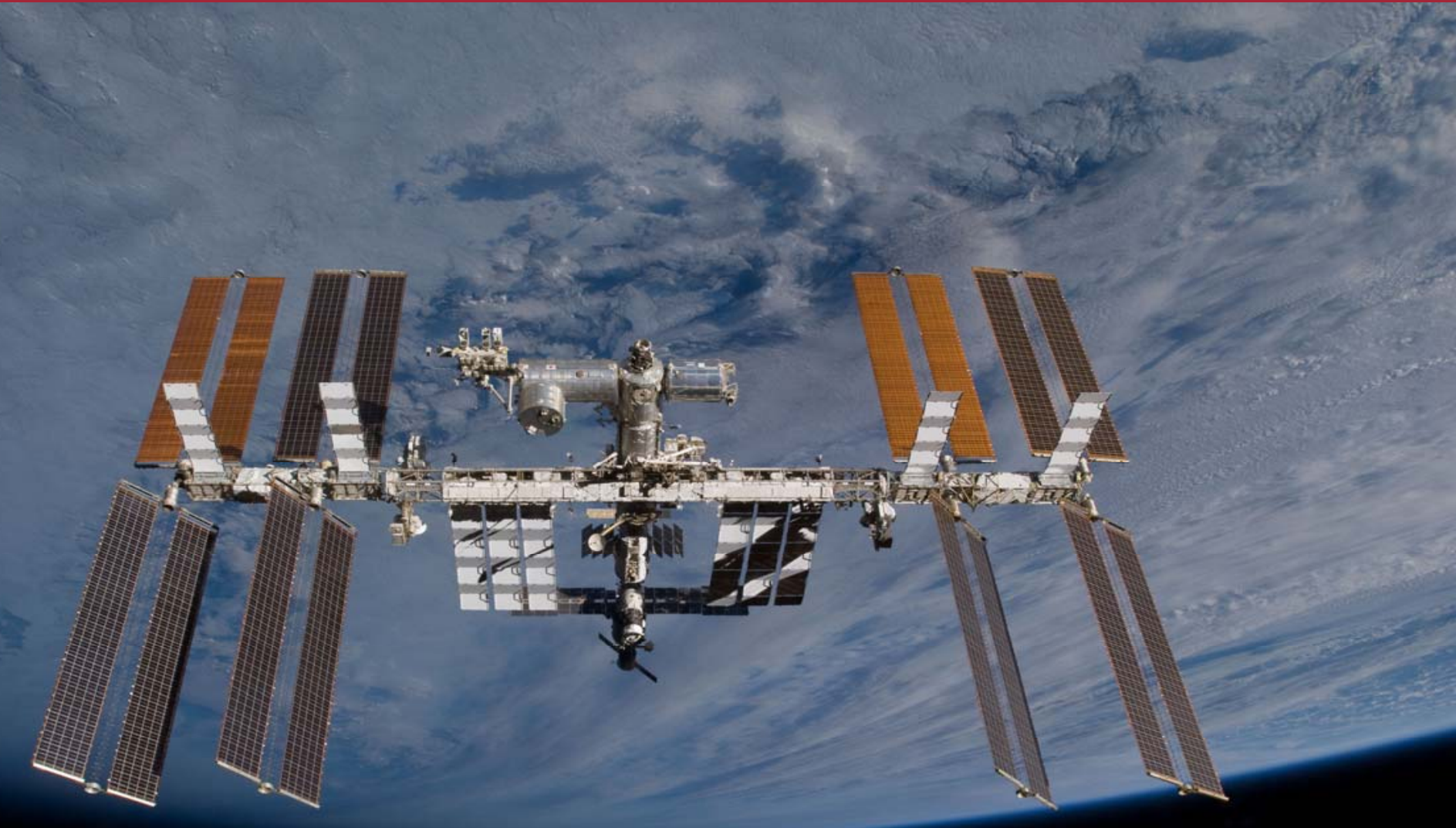

\section{ISS 2010}




\section{Examination of Surface Residuals Obtained during Re-Lubrication of the ISS SARJ}

Engineering, Operations \& Technology | Boeing Research \& Technology

Materials \& Fabrication Technology

A SARJ Event Logger

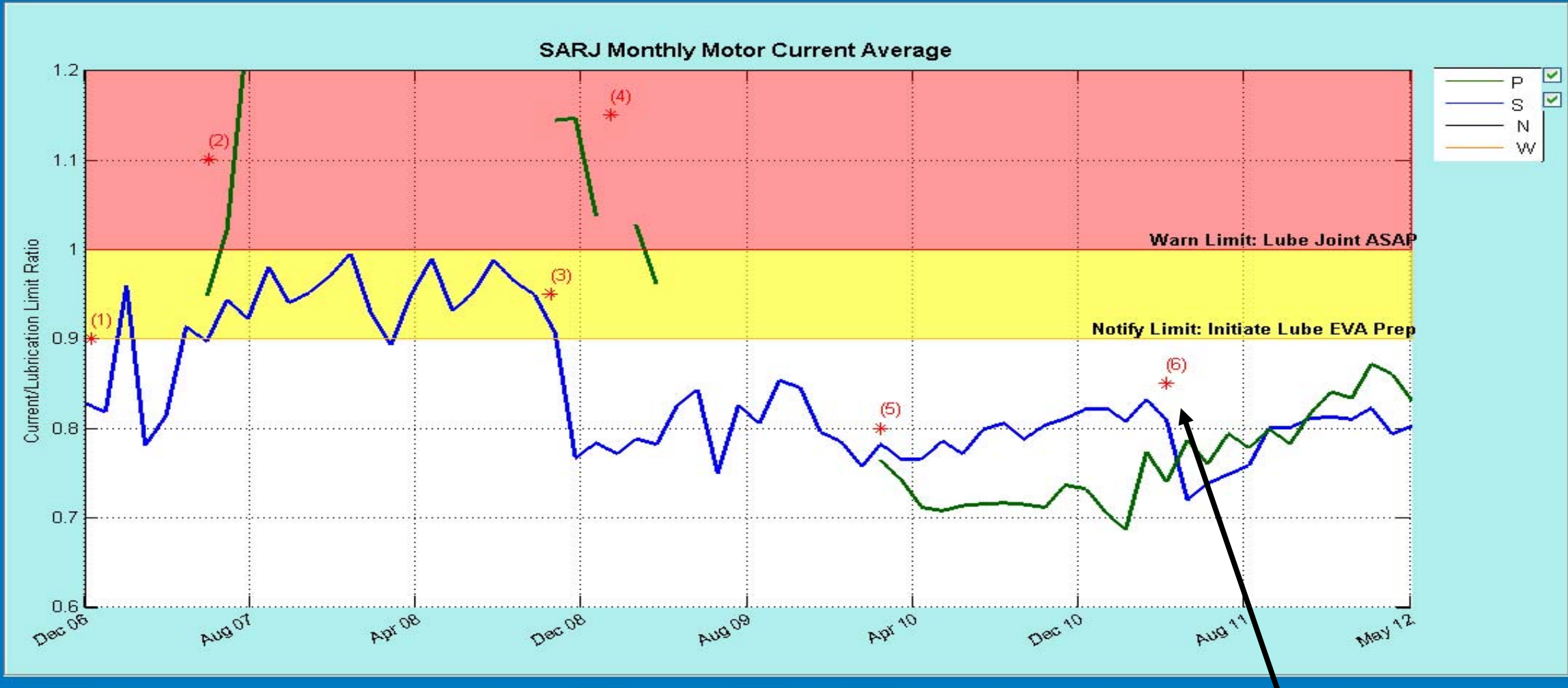

12/11:06, 01:26 Port $\vee$ SARJ Activation

06/04/07, 19:50 STBD $\vee$ SARJ Activation

09/1307, 19:10 STBD $\vee$ SARJ Anomaly

10/23:07, 01:35 STBD $\vee$ Park SARJ

10/25/08, 10:16 All $\quad \checkmark$ Lubricant Applied

01/23/09, 04:21 STBD $\vee$ Autotrack Tests

03/01/10, 04:50 STBD $\vee$ Return to Autotrack

05:01/11,12:42 Port $\vee$ Re-lubrication

\begin{tabular}{|l|c|}
\hline$\square$ & $(1)$ \\
$\square$ & $(2)$ \\
$\square$ & - \\
$\square$ & - \\
$\square$ & $(3)$ \\
$\square$ & $(4)$ \\
$\square$ & $(5)$ \\
$\square$ & $(6)$ \\
\hline
\end{tabular}

Relubrication Event, when sampling was conducted. 


\section{Examination of Surface Residuals Obtained during Re-Lubrication of the ISS SARJ}

\section{Outer Canted Surface Wiper}
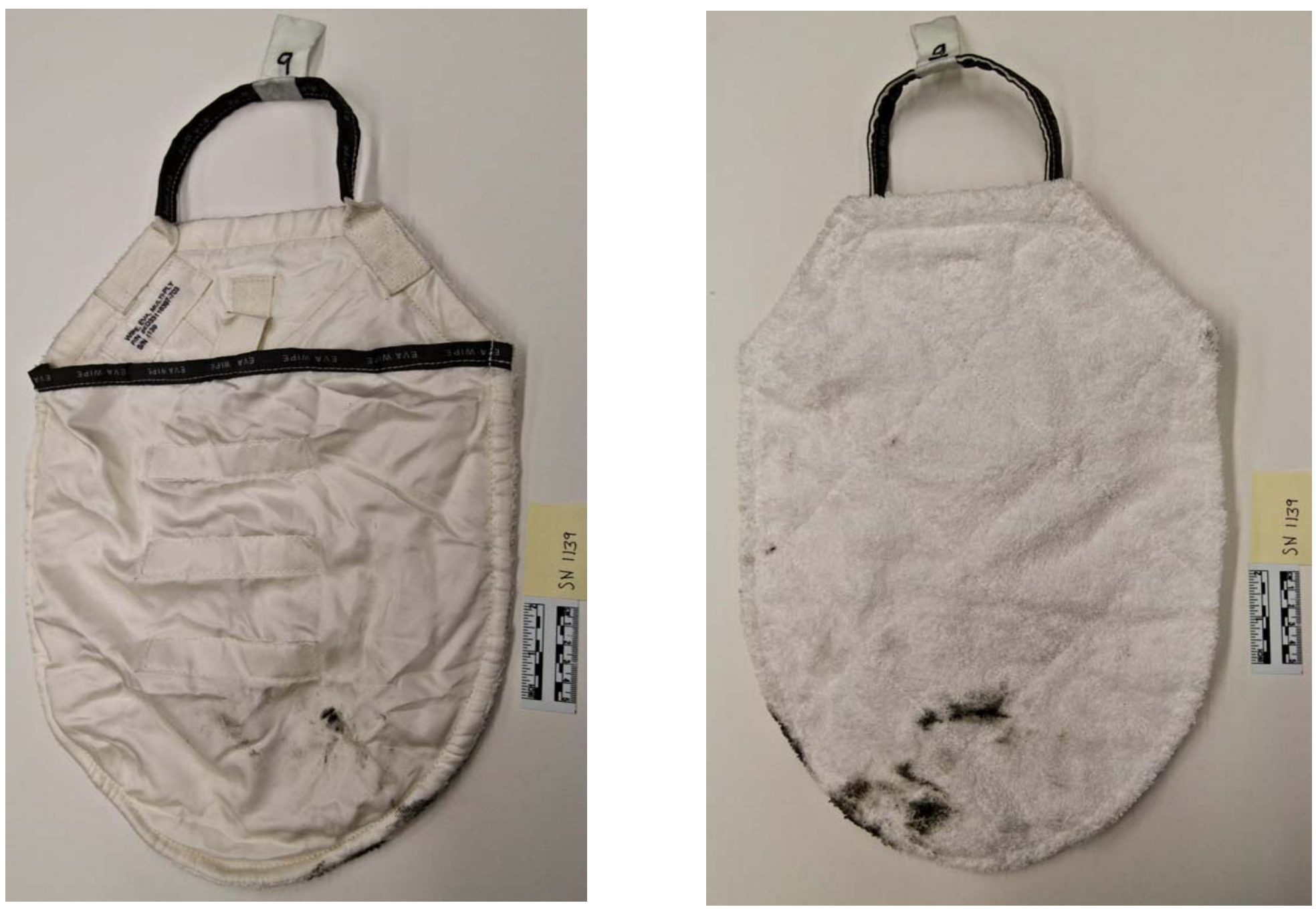


\section{Examination of Surface Residuals Obtained during Re-Lubrication of the ISS SARJ}

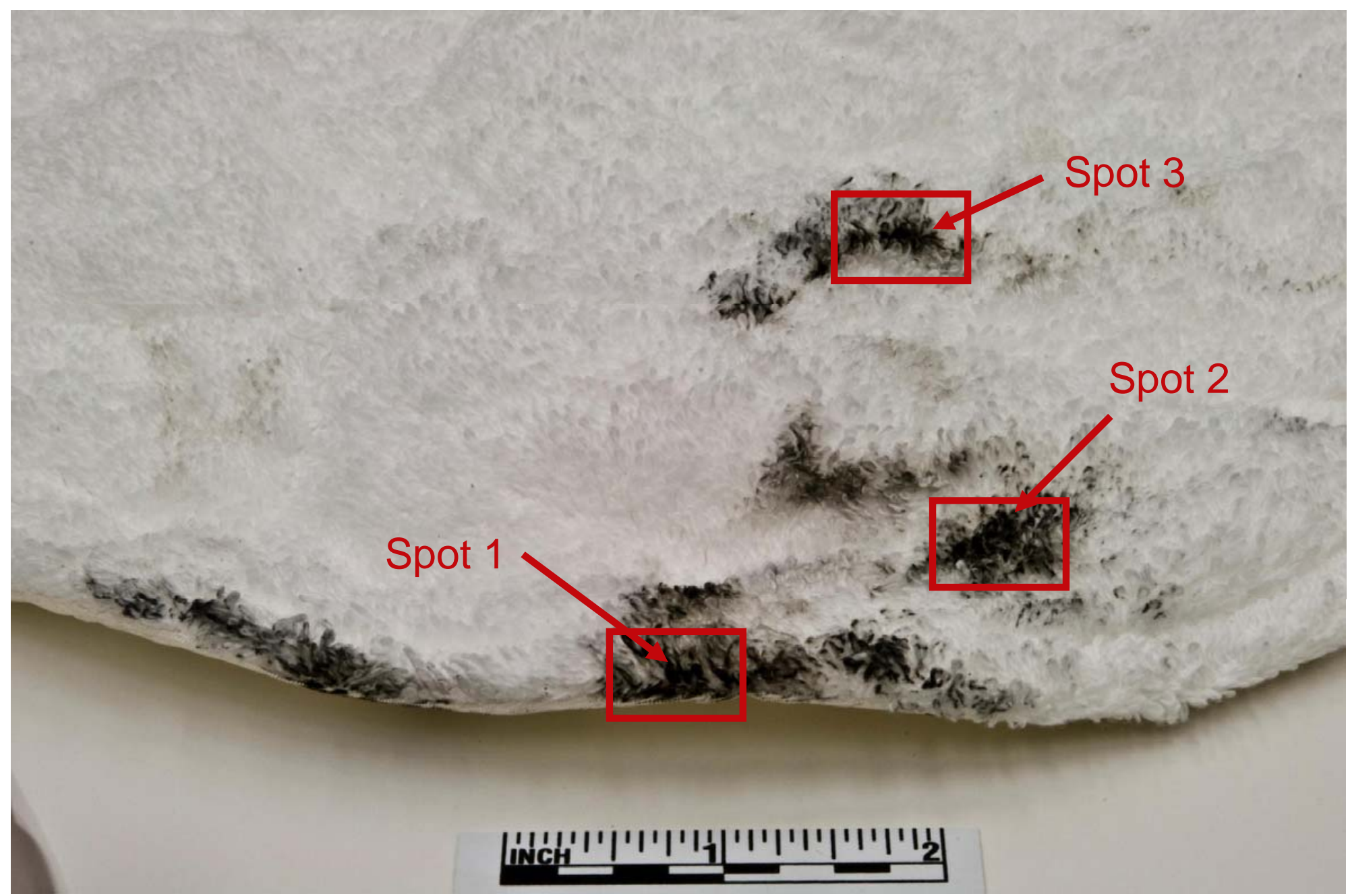




\section{Examination of Surface Residuals Obtained during Re-Lubrication of the ISS SARJ}

10x or so magnification used to scan the sample for areas of interest

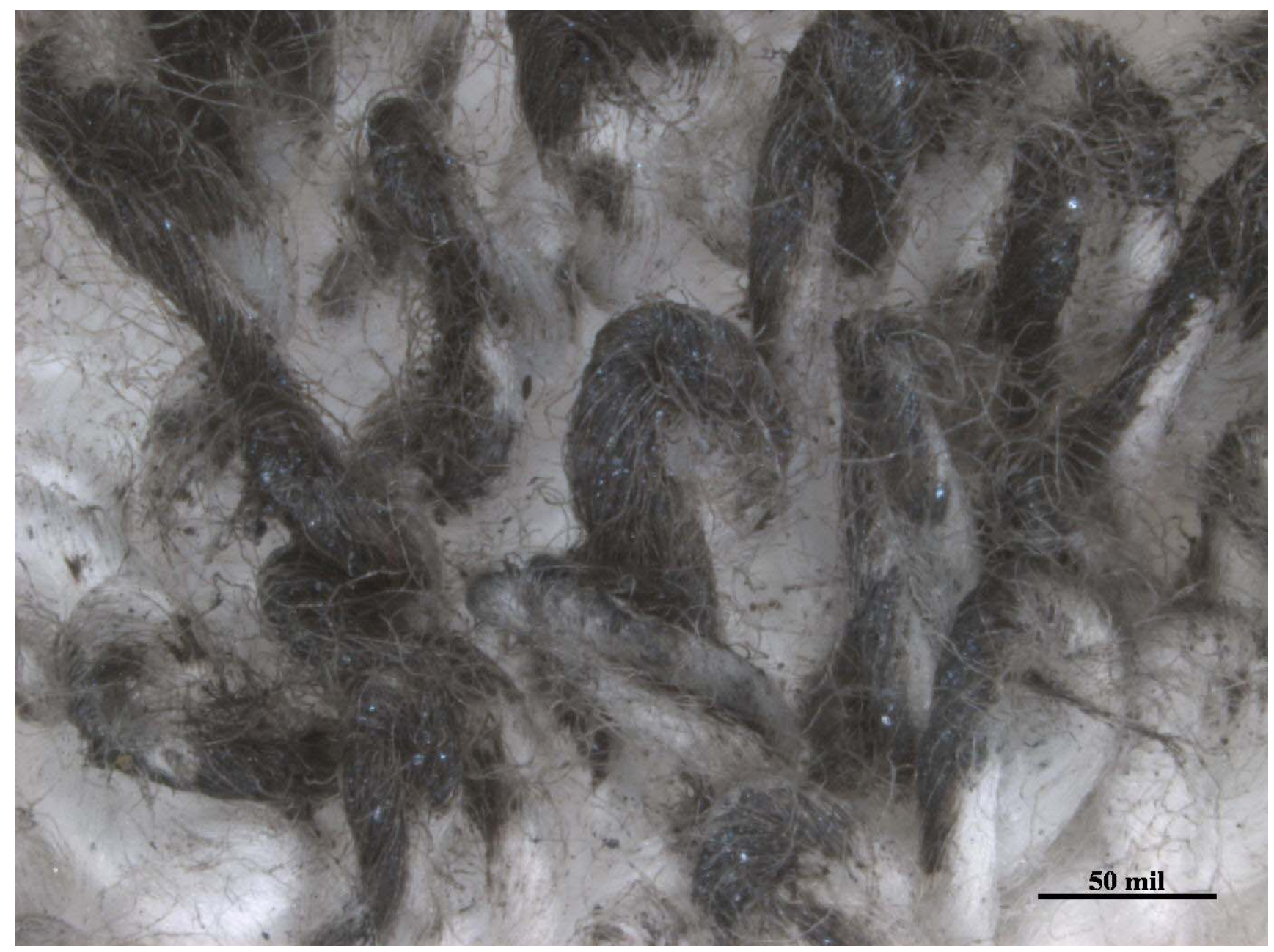




\section{Examination of Surface Residuals Obtained during Re-Lubrication of the ISS SARJ}

20x used to scan areas of interest for areas to harvest ("metallic" particles visible)

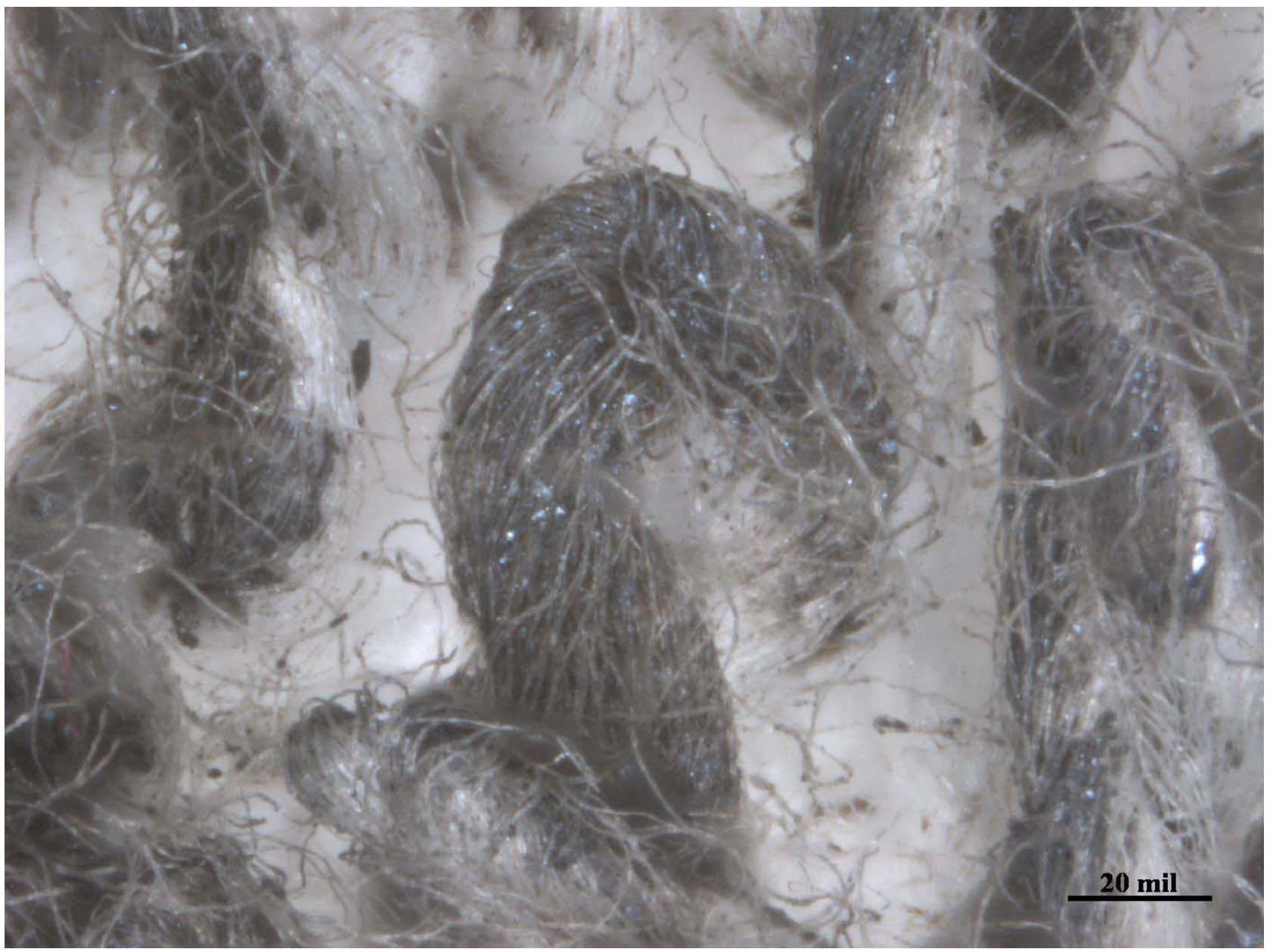




\section{Examination of Surface Residuals Obtained during Re-Lubrication of the ISS SARJ}

Harvested Yarn, on Carbon Tape for SEM Analysis

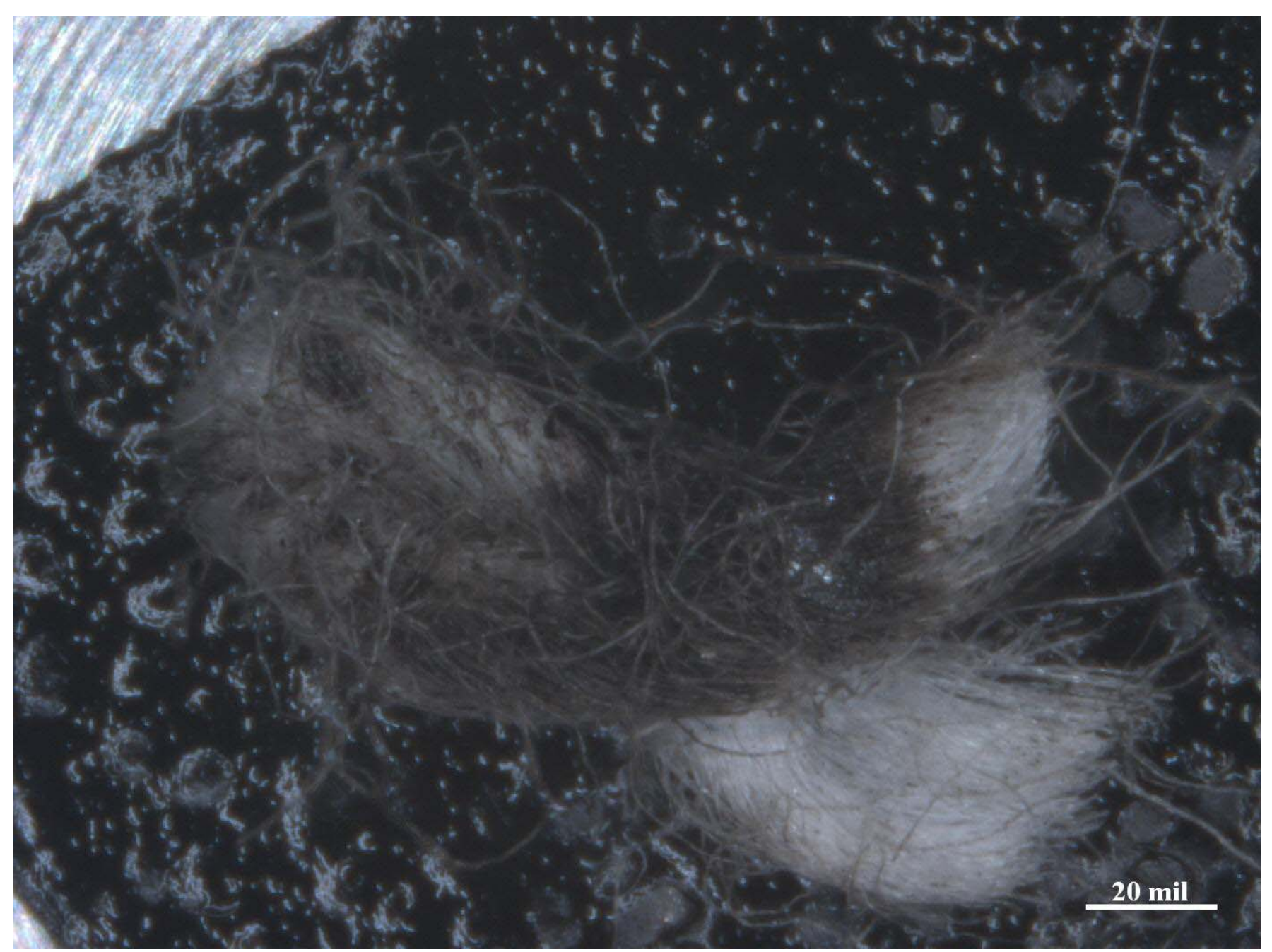




\section{Examination of Surface Residuals Obtained during Re-Lubrication of the ISS SARJ}

Backscatter Image, showing 15-5PH steel debris and $\mathrm{MoS}_{2}$ (from lubricant)

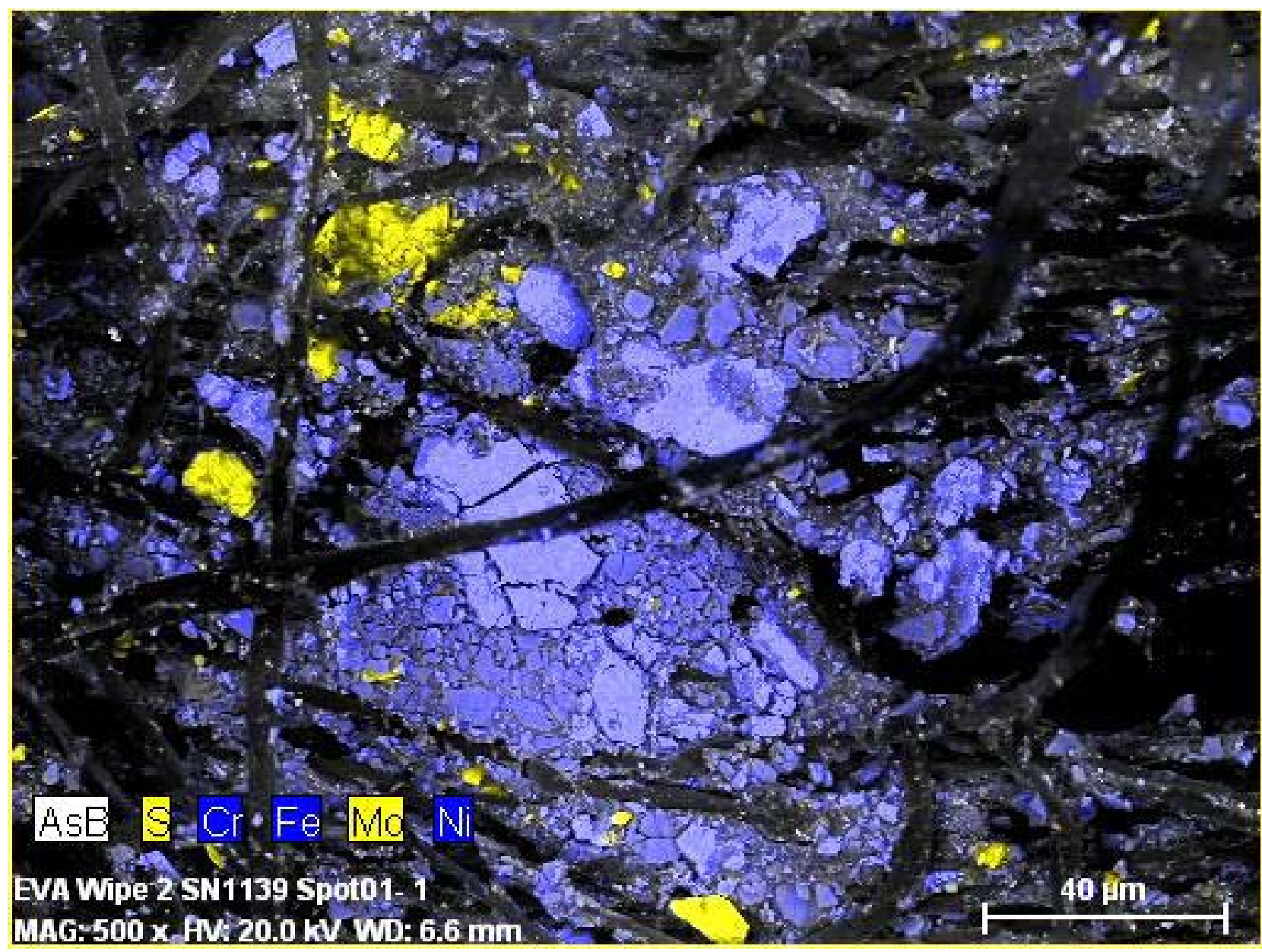




\section{Examination of Surface Residuals Obtained during Re-Lubrication of the ISS SARJ}

Backscatter Image in Variable Pressure mode. Most particles are $\mathrm{MoS}_{2}$, but one looked interesting.

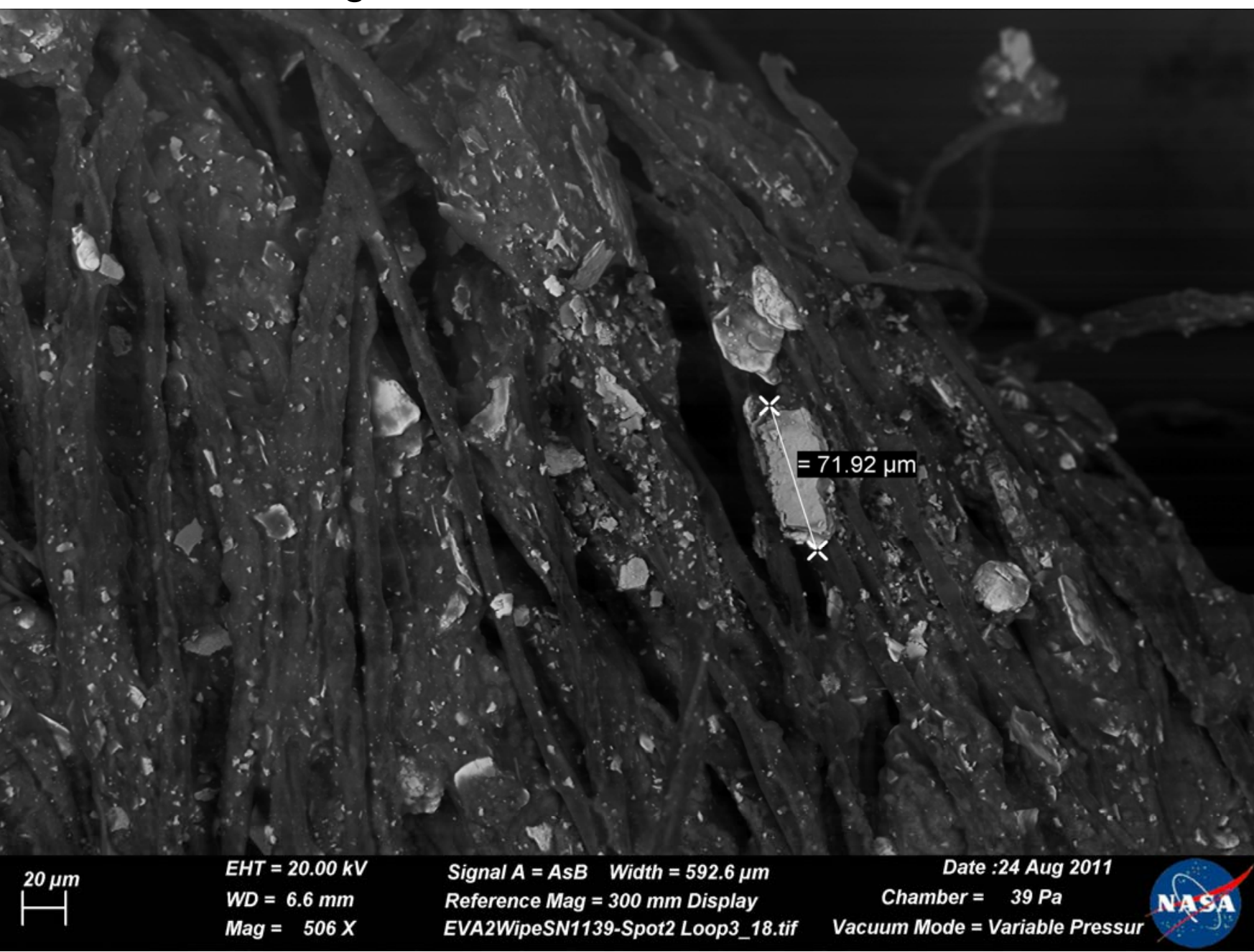




\section{Examination of Surface Residuals Obtained during Re-Lubrication of the ISS SARJ}

Again, Backscatter Image in Variable Pressure mode but higher magnification.

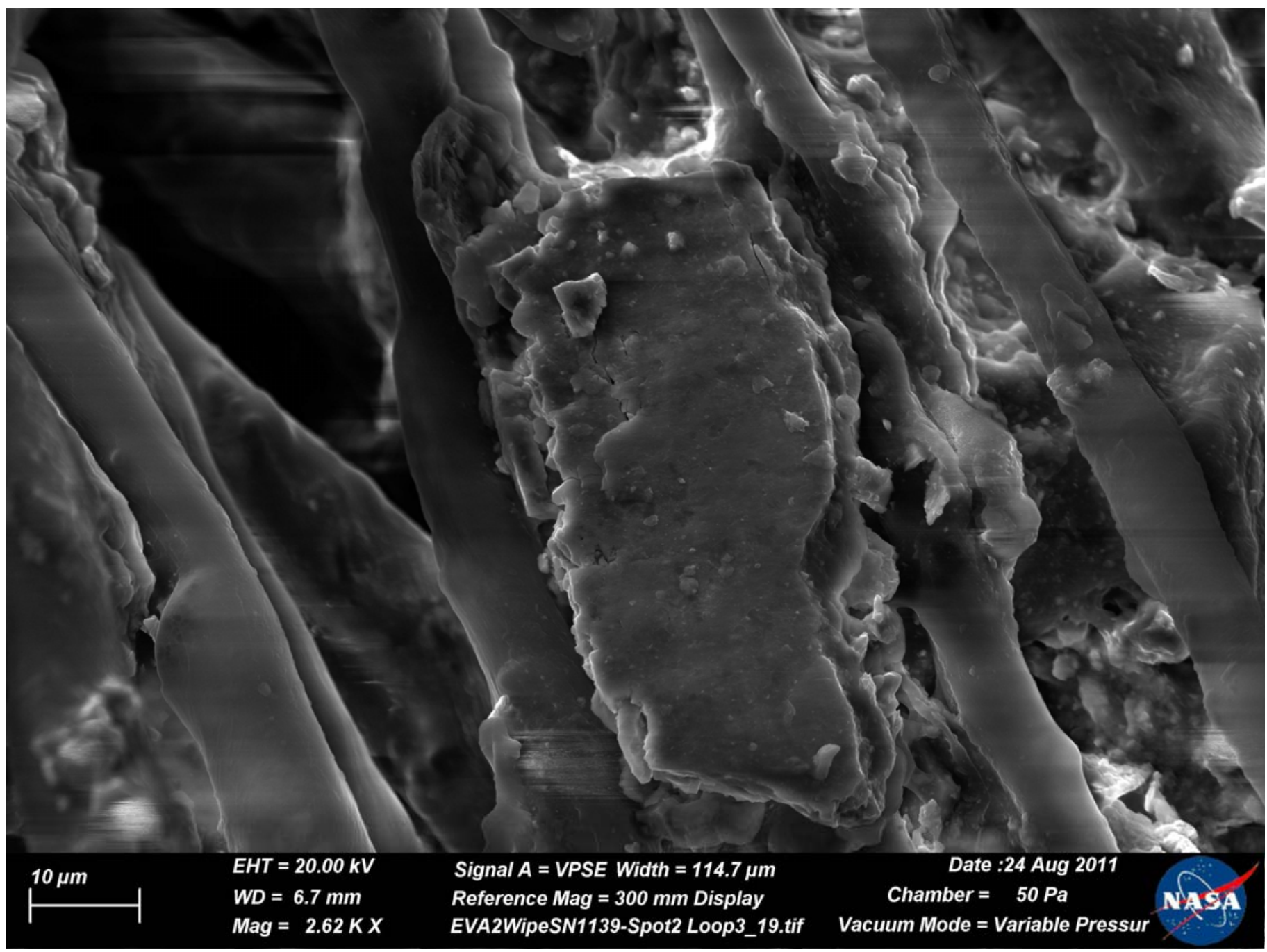




\section{Examination of Surface Residuals Obtained during Re-Lubrication of the ISS SARJ}

EDS analysis of particle is consistent with nitrided 15-5PH with a strong oxide signature.
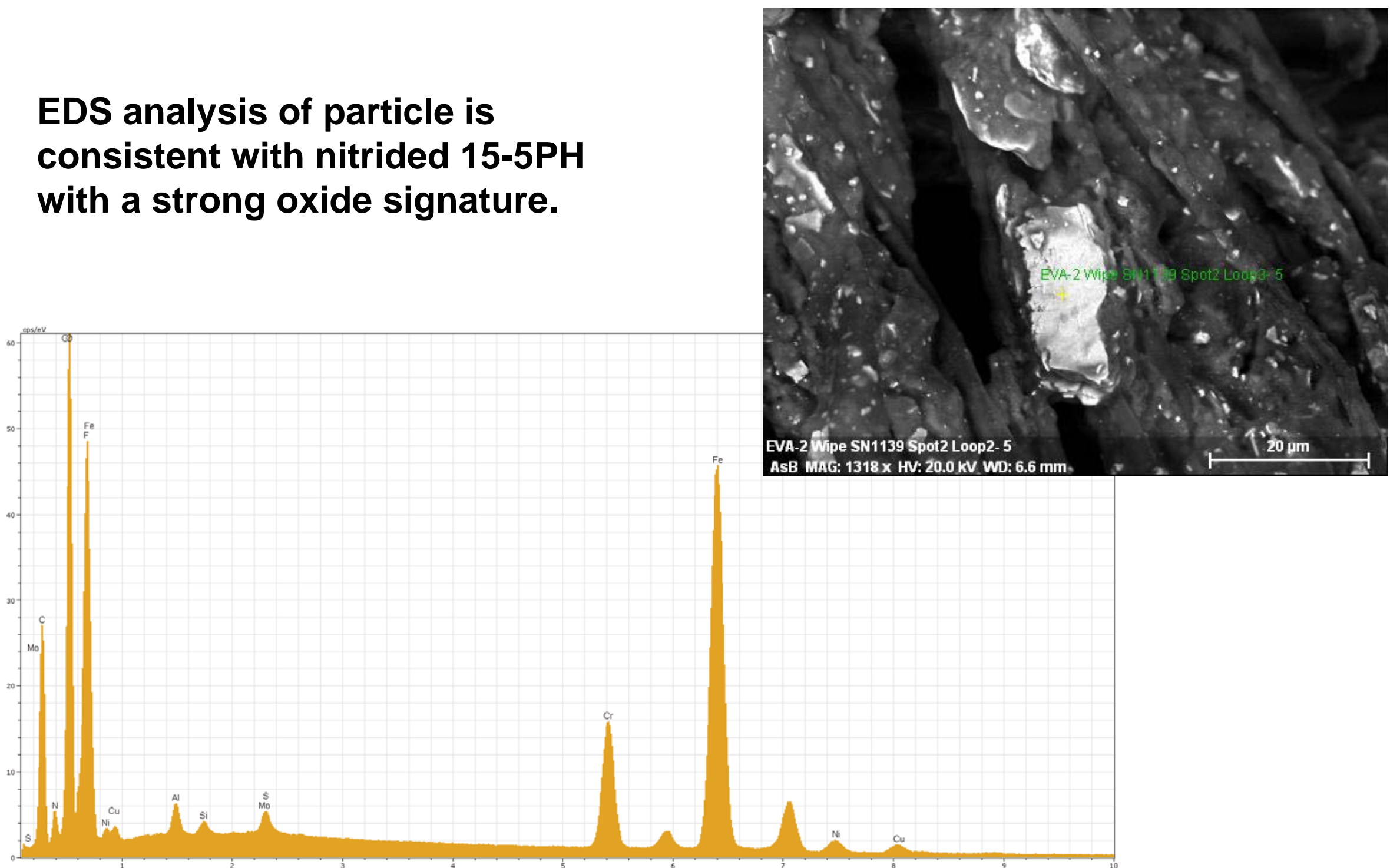


\section{Examination of Surface Residuals Obtained during Re-Lubrication of the ISS SARJ}

Highresolution Secondary Electron (SE2) image of Nitrided 155PH debris.

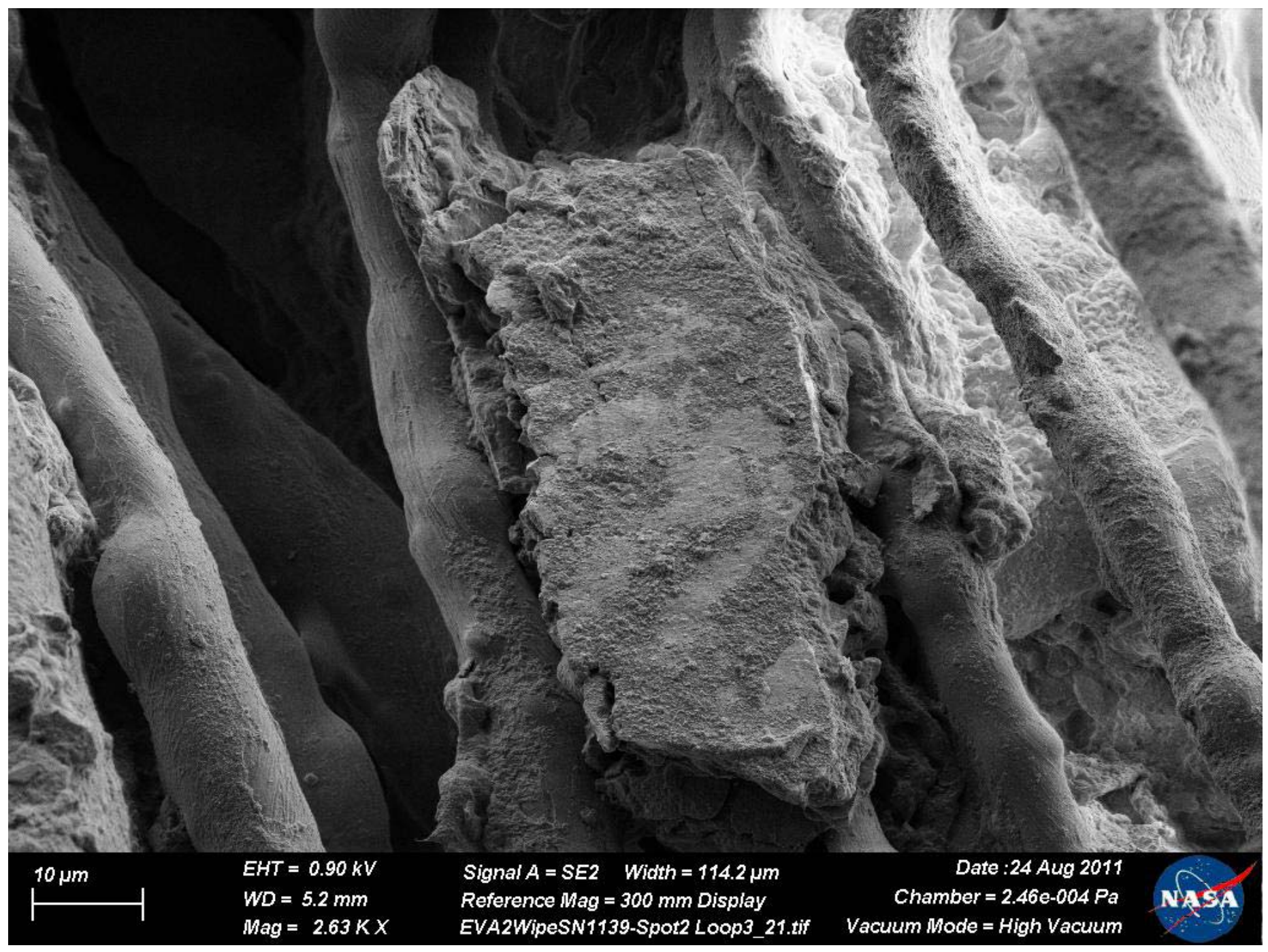

ASM Houston Failure Analysis Seminar J.L.Golden 03 April 201224 


\section{Examination of Surface Residuals Obtained during Re-Lubrication of the ISS SARJ}

Higher magnification Highresolution Secondary Electron (SE2) image of Nitrided 15$5 \mathrm{PH}$ debris.

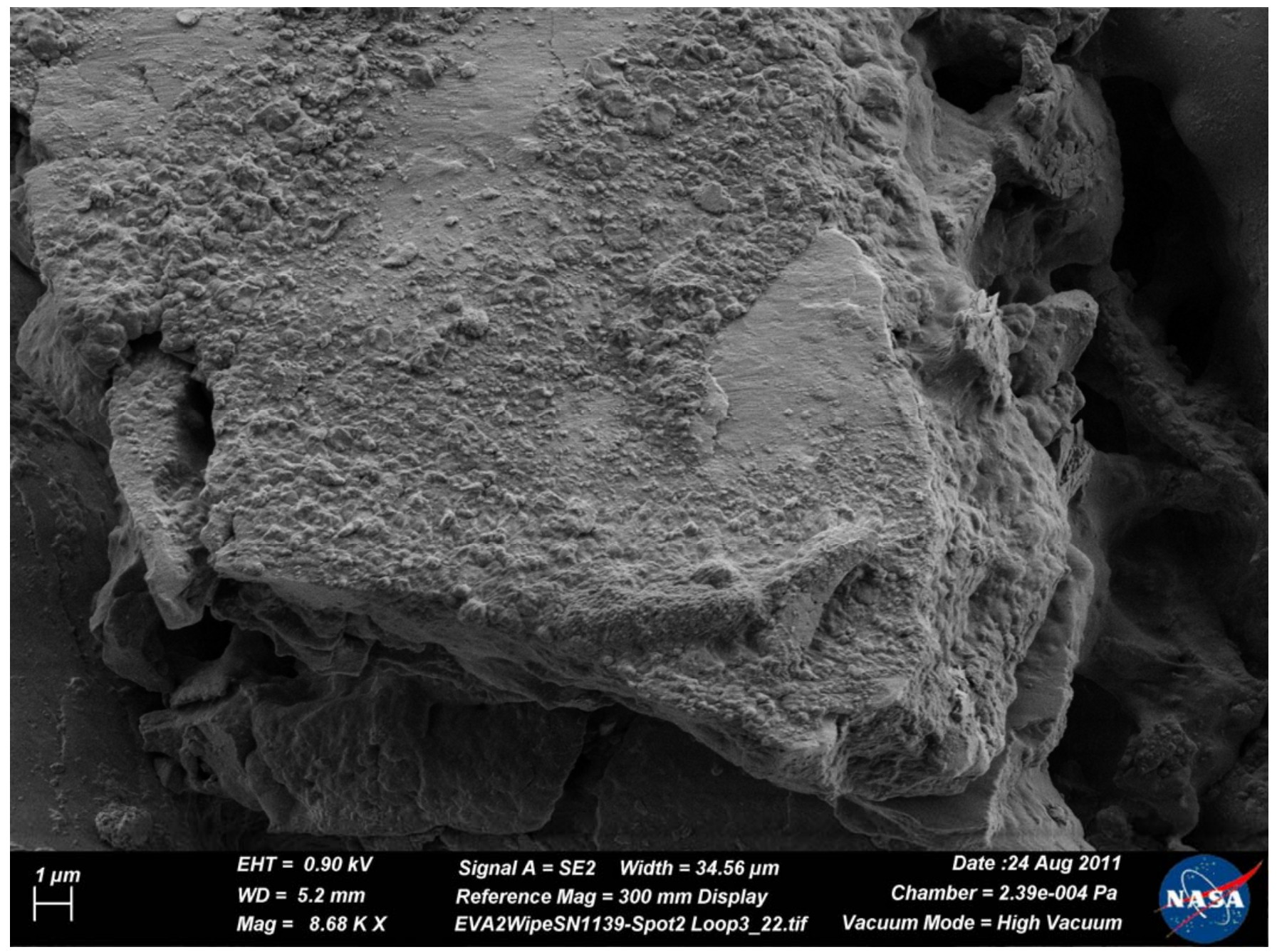




\section{Examination of Surface Residuals Obtained during Re-Lubrication of the ISS SARJ}

\section{Largest}

particle was found during prep for GC_MS; it measured 500 $\mu \mathrm{m}$ in greatest chord length, was very thin and flat.

Confirmed as nitrided 15-5PH but with a high oxygen peak.

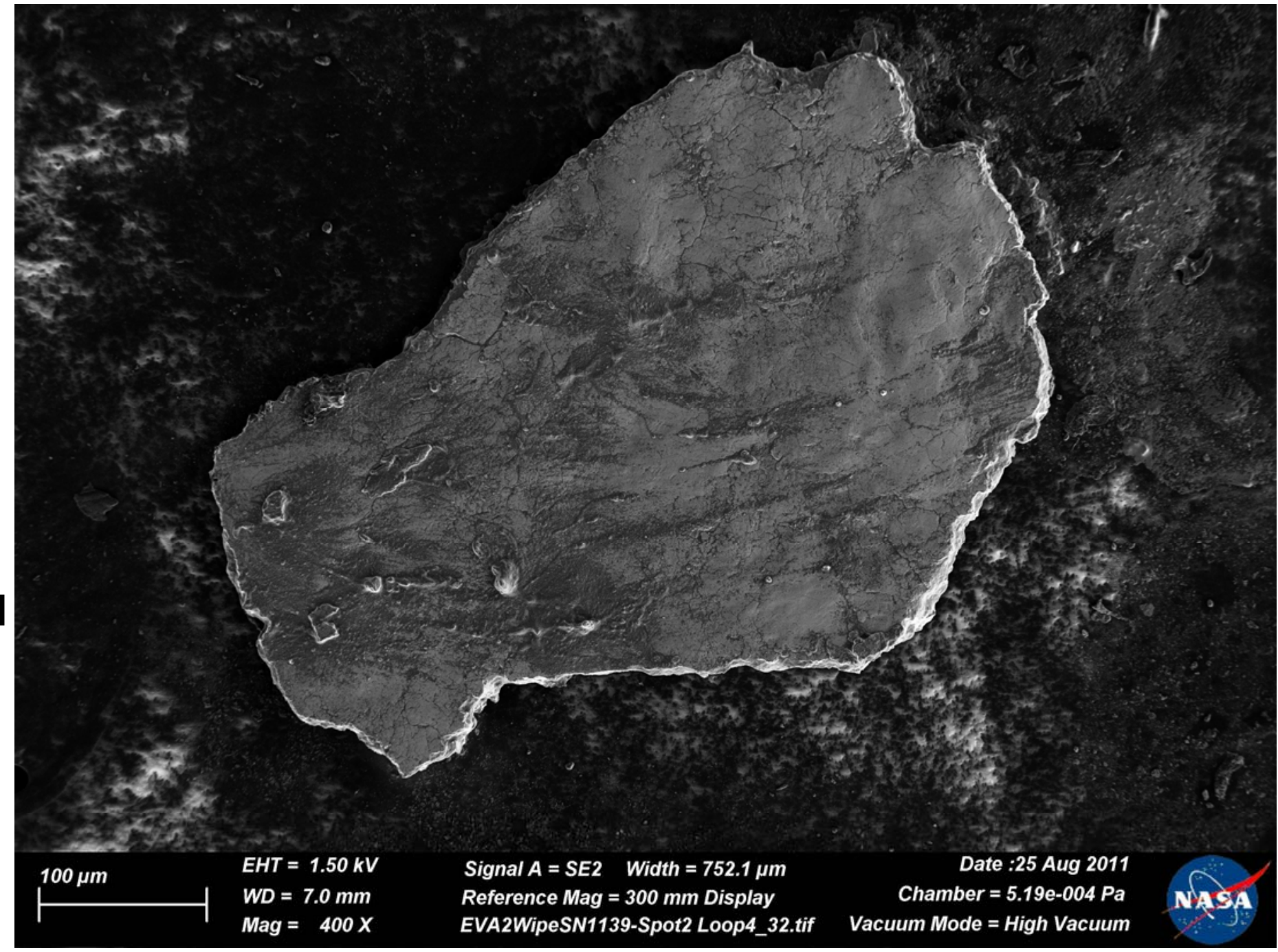




\section{Examination of Surface Residuals Obtained during Re-Lubrication of the ISS SARJ}

Engineering, Operations \& Technology | Boeing Research \& Technology

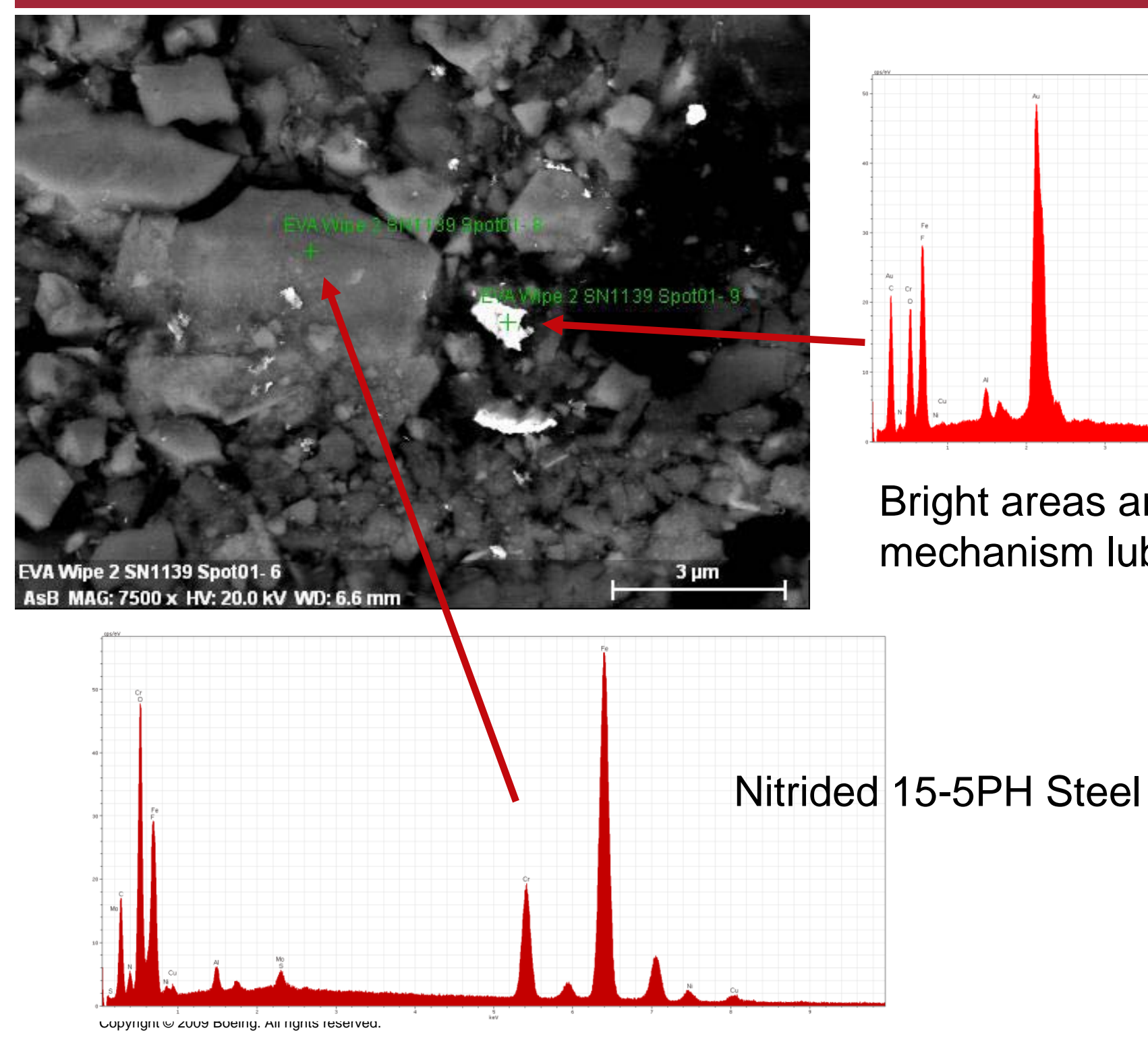

Materials \& Fabrication Technology 


\section{Examination of Surface Residuals Obtained during Re-Lubrication of the ISS SARJ}

- Microanalyses were also conducted to assess the condition of the oil-fraction in the grease.

- FT-IR Spectroscopy of extractions

- Thermo-Gravimetric Analyses

- Pyrolysis Gas Chromatograph - Mass Spectrometry

- Results all indicate that the oil has been chemically altered. 


\section{Examination of Surface Residuals Obtained during Re-Lubrication of the ISS SARJ}

- Conclusions

- Wear debris from the race ring surface (nitrided 15-5PH steel) was observed, but not in alarming quantity, particle size, or particle morphology.

- Many of the wear debris particles appeared oxidized, suggesting pre-flight formation.

- Indications are that the port-SARJ was on the same path to eventual nitride failure, though fortunately lagging behind, and was likely saved from significant race ring surface damage by the lubrication.

- Most surprising result was the lack of sample, the limited grease apparently applied during lubrication.

- Monitoring of mechanism telemetry will continue, with the relubrication interval driven by that data.

- Future wipe samples expected to be taken on relubrication. 


\section{Q BDEINE}

